\title{
ALTERACIONES CLINICAS Y TISULARES PRODUCIDAS POR LARVAS DE Ascaris suum en Mus musculus var. albinus INFECTADOS EXPERIMENTALMENTE
}

Victorino Delgado Tello ${ }^{\prime}$; Rosa Maria Liñan Abanto

\begin{abstract}
RES U MEN
El presente trabajo tuvo como objetivo determinar las alteraciones clínicas y tisulares producidas por larvas de Ascaris suum en Mus musculus var. albinus.

Los especimenes de Mus musculus fueron infectados por vía oral con una dosis de 3800 huevos. Las alteraciones clinicas fueron: respiración acelerada y ronquidos.

Las alteraciones observadas en los cortes histológicos del pulmón fueron : infiltración por polimorfonucleares, transudado, presencia de tejido fibroso y porciones de larvas.

Se concluye que el cuadro clinico y tisular observado en los especimenes es causado por Ascaris suum.

\section{A B S T R A C T}

The object of this work was to determined the clinics and tissue alterations caused by larvae of Ascaris suum in Mus musculus var. albinus. The specimens of Mus musculus were infected orally with 3800 eggs. Clinics alterations were rapid respiration and snore were observed. Alterations observed in the cut of pulmonary tissue were infiltration by polimorphonucleares, transuded, fibrous tissue and remains of larvae were observed. In conclusion the clinics and tissue alterations observed in the specimens is caused by larvae of Ascaris suum.
\end{abstract}

\section{INTRODUCCIÓN}

La ascariosis es una de las principales parasitosis del hombre causada por el nematodo Ascaris lumbricoides, el cual se encuentra ampliamente distribuido en el mundo, principalmente en regiones húmedas, tropicales y templadas( Atías, 1997). Existe una especie parásita del cerdo conocida como A. suum, según Maldonado (1965) ambas especies se diferencian por la configuración diferente que tienen los dentículos de los tres labios orales, y considera que ambas formas son variaciones fisiológicas de una forma primitiva que fue original a uno u otro huésped.

En el intestino delgado del huésped se localizan los parásitos adultos, cuyas hembras albergan en su útero aproximadamente 26 millones de huevos, con una oviposición diaria de 200,000 , que salen con la materia fecal.En el medio ambiente y en un periodo de tres semanas se desarrolla dentro del huevo la larva de segundo estado(L2), la cual se libera en el intestino del huésped para penetrar en la pared intestinal, y por vla sanguínea llegar a los pulmones en donde dan lugar a las larvas de tercer y cuarto estado(L3-L4),en aproximadamente 11 dias; luego, las larvas ascienden por el árbol respiratorio para ser deglutidas, regresando al intestino delgado en donde continúan su desarrollo hasta llegar al estado adulto(Goldsmith y Heyneman, 1995).

Existen dos tipos de ascariosis la intestinal producida por los adultos y la pulmonar ocasionada por los estadios larvales de A.lumbricoides y A.suum. La patogenia de la ascariosis pulmonar se manifiesta por la ruptura que producen las larvas en los capilares pulmonares, paredes y tabiques alveolares, ocasionando focos de microhemorragia. Se observan infiltrado linfoplasmocitarios eosinofilicos en tabiques y alvéolos, con congestión y exhudado que se manifiesta clínicamente como una neumonitis (Pérez y Gonzáles, 1994; Heggers y cols., 1995).

El cuadro de neumonitis en el humano puede ser causado también por las larvas de tercer y cuarto estado(L3-L4) de A. suum, habiéndose demostrado la existencia de infección cruzada, aunque poco frecuente; sin embargo, estas larvas no llegan al estado adulto(Goldsmith y Heyneman, 1995)

En ciertos sectores de la población peruana existe desinformación de los efectos de esta parasitosis, así como de su forma de transmisión y de las patologias que podría estar ocasionando a nivel pulmonar, con las consiguientes manifestaciones clínicas, sobre todo

\footnotetext{
(1) Biólogo Pesquero

(2) Magister en Ciencias Parasitología
} 
en los niños. Todo esto, ocasionado porque en el Perú, si bien se han realizado investigaciones en cuanto a la ascariosis intestinal por lo cual podemos decir que es un problema de salud pública y esta presente en casi todo el territorio. En cuanto a la ascariosis pulmonar, ya sea aquella producida por larvas de $\mathrm{A}$. lumbricoides o A. suum, no se han realizado investigaciones.

Por todo lo expuesto anteriormente, nos propusimos realizar una investigación que tuvo como objetivo: Determinar las alteraciones clinicas y tisulares producidas por larvas pulmonares de A. suum en especimenes de Mus musculus var. Albinus infectados experimentalmente.

\section{MATERIAL Y MÉTODOS}

\section{Material de estudio:}

La muestra estuvo constituida por :

- 08 especimenes de Mus musculus var. albinus de ambos sexos y de aproximadamente un mes de edad, procedentes del bioterio de la UNJBG-Tacna.

- Huevos infectivos $\left(L_{2}\right)$ de A.suum obtenidos después de cultivarlos en formol al $2 \%$.

\section{Técnicas y métodos de trabajo:}

\subsection{Diseño de la investigación:}

El diseño empleado en la investigación fue el clásico (Falcón y Cols., 1978).

Antes Después

$\begin{array}{lll}\text { Grupo experimental- } & \text { A } & A^{n} \\ \text { Grupo testigo } & \text { B } & B^{\prime \prime}\end{array}$

Las variables estudiadas fueron:

Variable independiente : larvas infectivas de A. suum.

Variable dependiente: Alteraciones clínicas e histopatológicas.

\subsection{Distribución del material de estudio:}

El grupo experimental y testigo estuvo formado por 06 y por 02 especímenes respectivamente, que fueron distribuidos en jaulas independientes.

\subsection{Obtención de los huevos infectivos:}

Del intestino de cerdos sacrificados se recolectaron hembras maduras de A. suum, las cuales fueron transportadas en solución salina fisiológica (S.S.F) al laboratorio, donde se practicó la disección y extracción de los úteros grávidos. Con la ayuda del estéreo microscopio y estiletes se rompió las paredes del útero para liberar los huevos, los cuales fueron lavados varias veces con S.S.F. por sedimentación y decantación. Los huevos libres de tejido uterino fueron cultivados por cuatro semanas en una solución de formol al $2 \%$ y a una temperatura de $28^{\circ} \mathrm{C}$, hasta obtener los huevos infectivos.

\subsection{Infección de ratones:}

Cada espécimen del grupo experimental fue inoculado por vía oral con $0.5 \mathrm{ml}$. de una suspensión que contenía 3800 huevos infectivos de A. suum, en una sola dosis. Previamente a cada espécimen se le realizó un análisis coproparasitológico mediante una técnica directa para descartar la presencia de parásitos intestinales que pudieran hacer ciclo pulmonar. Los especimenes fueron mantenidos en jaulas y se les proporciono alimentos controlados para evitar la transmisión de otros parásitos.

\subsection{Para observación de alteraciones clínicas:}

En el transcurso de la experiencia se evaluó diariamente a los especimenes experimentales y testigos, con el objeto de observar alguna alteración clínica producto de la infección pulmonar.

\subsection{Para observación de alteraciones tisulares:}

En los ratones muertos y sacrificados durante la experiencia tanto en los experimentales como en los testigos se disectó lo pulmones y se realizo observaciones macroscópicas, tratando de encontrar alguna alteración en estos órganos en cuanto al aspecto, tamaño y color. Para las observaciones microscópicas se realizaron aplastamiento de porciones de tejido entre dos laminas portaobjeto y observados a mediano aumento. Además, se realizaron cortes histológicos que fueron coloreados con la técnica hematoxilina/eosina. Para determinar el daño producido en el tejido se realizaron observaciones microscópicas de los cortes histológicos.

\section{RESULTADOS}

El desarrollo de huevos larvados $\left(L_{2}\right)$ de $A$. suum se logro a los 30 dias de cultivarlos en formol al $2 \%$ y a una temperatura de $28^{\circ} \mathrm{C}$. Pero la obtención de huevos infectivos $\left(L_{2}\right)$ se obtuvo a los 45 dias de cultivo(Anexo 1 ).

Las alteraciones clínicas en los especimenes de Mus musculus var. albinus se observaron a partir del quinto día de infección y éstas fueron: respiración rápida, ronquidos, sibilancias, erizamiento de pelo, 
encorvamiento y perdida de peso. Al séptimo día los especimenes murieron producto de la infección. Estas alteraciones se observaron en todos los especimenes experimentales menos en los testigos.

En cuanto a las alteraciones histológicas macroscópicas se observó que los pulmones presentaban un aspecto hemorrágico y edematosos. Alteraciones que no se observaron en los pulmones de los testigos.(Anexo 2).

Al realizar las observaciones microscópicas de los squash" y de lo cortes histológicos se observó nítidarnente la presencia de las larvas en el tejido pulmonar(Fig. 1). Además, se observó en los cortes histológicos alteraciones como son : infiltración por polimorfonucleares neutrófilos y eosinófilos, abolición del parénquima pulmonar, transudado y presencia de tejido fibroso(Fig. 2).

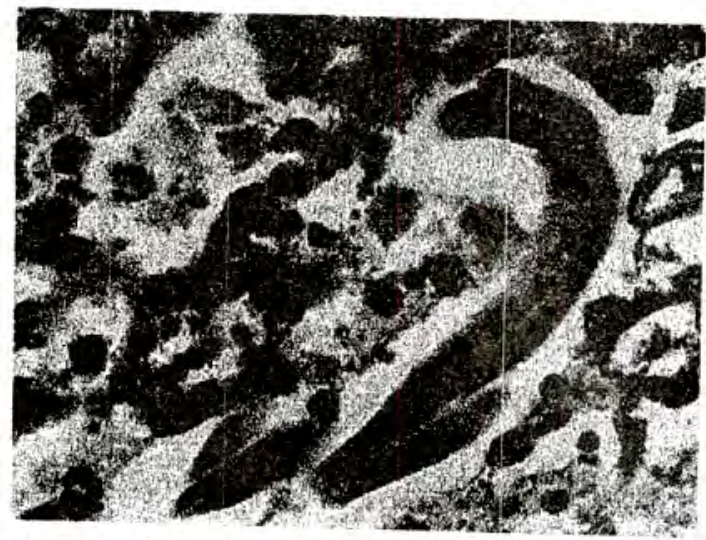

Fig. 1: Corte histológico de pulmón de M. musculus var. albinus donde se observa una larva pulmonar de A. suum en el parénquima.

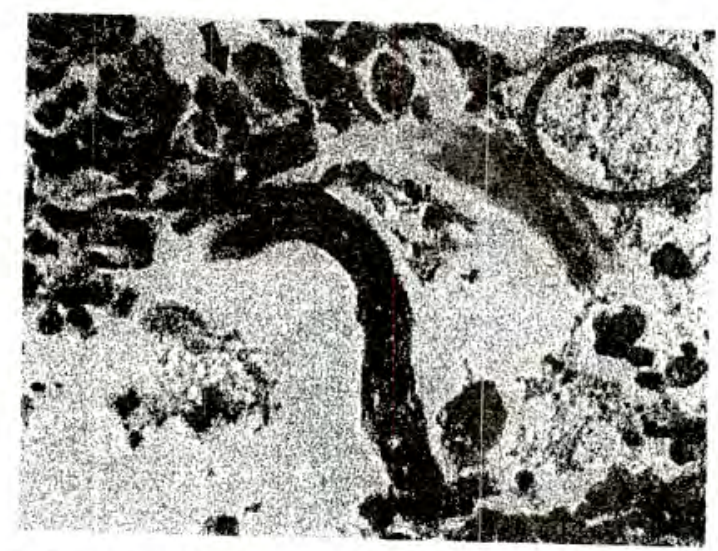

Fig. 2: Corte histológico de pulmón de M. musculus var.albinus donde se observa infiltrado por polimorfonucleares, transudado y tejido fibroso.

\section{DISCUSIÓN}

En la presente investigación se logró el desarrollo de huevos con $\mathrm{L}_{2}$ de Ascaris suum a los 30 dias de cultivo en solución de formol al $2 \%$ y a una temperatura de $27^{\circ} \mathrm{C}$, resultado que difiere con lo reportado por Echenique y Magaró, (1997) quienes lograron desarrollar la mencionada forma evolutiva a los 14 dias de cultivo, pero se debe tener en cuenta que ellos trabajaron con una temperatura de $37^{\circ} \mathrm{C}$. Si bien en el tiempo mencionado se logro el desarrollo de huevos con $L_{2}$ fue necesario prolongar el cultivo por 15 dias más debido a que el trabajo experimental realizado por otros investigadores (Escalante y Liñán, 2002) ha demostrado que los huevos de $A$. suum no son infectivos inmediatamente después que se ha formado la larva 2. Se debe señalar, que para la identificación de la forma evolutiva mencionada se tuvo en cuenta la doble cutícula que presenta producto de la primera muda.

Las alteraciones clínicas que presentaron los especimenes de Mus musculus var. albinus infectados fueron principalmente de tipo respiratorio como respiración rápida, ronquidos y sibilancias, estas alteraciones clínicas son reportadas por otros investigadores ya sea para su hospedero natural $u$ otros hospederos experimentales (Lapage, 1971; Heggers y cols., 1995), lo cual demuestra que el principal daño producido por los estadios larvales en su recorrido por diversos órganos lo realiza en los pulmones, pues deben salir de ellos vía ascendente tratando de llegar a la faringe para ser deglutidos y luego llegar al intestino delgado

En cuanto a las alteraciones macroscópicas del tejido pulmonar se observó que el daño fue muy intenso del pulmón, pues estaban totalmente hemorrágicos y edematosos. Estas alteraciones son consecuencia de la penetración de las larvas desde los capilares sanguineos hacia los alvéolos pulmonares en su ascenso hacia el árbol respiratorio y como son ya relativamente grandes van a originar hemorragias y edema, y la intensidad del daño dependerá del número de larvas que migren a los pulmones.

En lo referente a las alteraciones histológicas microscópicas del pulmón que se encontró en esta investigación concuerda con lo reportado por otros investigadores(Atias, 1997; ). Estas alteraciones serian consecuencia de la presencia de las larvas en los espacios aéreos terminales lo cual determinaria la infiltración local por polimorfonucleares neutrofilos y eosinófilos, presencia de tejido fibroso. La presencia de transudado y la infiltración por neutrofilos y eosinófilos, taponaría los sacos aéreos y como consecuencia la respiración se dificulta seriamente. Esta situación es llamada neumonitis por Ascaris, que es lo que finalmente presentaron los especimenes infectados. 


\section{CONCLUSIONES}

1. Las alteraciones clínicas producidas en Mus musculus var. albinus por las larvas pulmoneres de $A$. suum son respiración rápida, ronquidos y sibilancias, lo cual podria describirse como una neumonitis.

2. Las alteraciones tisulares a nivel pulmonar en los especimenes infectados son infiltración por polimorfonucleares, transudado y presencia de tejido fibroso.

\section{REFERENCIA BIBLIOGRÁFICA}

1. Atias, A. 1997. Parasitología Clínica. 3ra ed. Publicaciones técnicas Mediterráneo. Santiago-Chile.

2. Echenique, C.G. y H.M. Magaró. 1997. Estudio de Ascaris lumbricoides en fase larvaria. Acta de Bioquím. Clin. Latinoam. 31(1):23-7.

3. Escalante, H. Y R. Liñán. 2002. Producción de anticuerpos en Oryctolagus cunniculus inmunizados con antigenos de EIS y somáticos de larvas pulmonares de Ascaris suum. Libro de resúmenes del $\mathrm{V}$ Cong. Per. de Parasit. Trujillo. Pág.125.

4. Falcón, P. 1978. Metodología de la Investigación. UNT
5. Golsdmith, R. y D. Heyneman. 1995. Parasitología y medicina tropical. Edit. EI Manual Moderno, S.A. de C.V. México.

6. Heggers, J.P.; Muller, M.J.; Elwood, E. and D. N. Herndon. 1995. Ascariasis pneumonitis: a potencially fatal complication en smoke inhalation. Burns. Mar. 21(2):149-51.

7. Lapage, G. 1971. Parasitologia veterinaria. Edit. Continental, S.A. Mexico.

8. Maldonado, J. F. 1965. Helmintiasis del hombre en América. Edit. Científico-Médica. Barcelona-España.

9. Pérez, O.M. y A.M. González. 1994. Relación de Neumonia y Parásitos de ciclo pulmonar en niños de 1 a 12 años. Boletín Médico de Postgrado. 10(3):192-5.

\section{ANEXO}

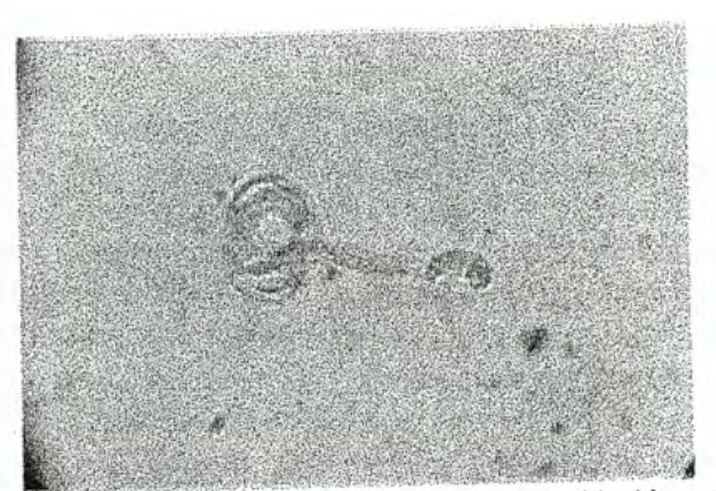

Anexo 1: Huevo infectivo de Ascaris suum obtenido por cultivo en una solución de formol al $2 \%$.

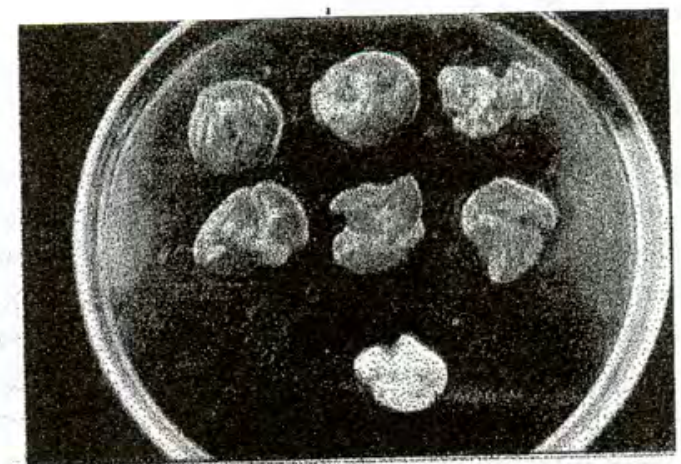

Anexo 2: En la parte superior se observa pulmones de ejemplares de Mus musculus var. albinus infectados con larva $(L 3-L 4)$ de A. suum . En la parte inferior se observa un pulmón no parasitado. 